\title{
Erratum to: Warfarin dose prediction in children using pharmacometric bridging - comparison with published pharmacogenetic dosing algorithms
}

\author{
Anna-Karin Hamberg • Lena E. Friberg • Katarina Hanséus • \\ Britt-Marie Ekman-Joelsson • Jan Sunnegårdh • Anders Jonzon • \\ Bo Lundell • E. Niclas Jonsson • Mia Wadelius
}

Published online: 10 August 2013

(C) Springer-Verlag Berlin Heidelberg 2013

Erratum to: Eur J Clin Pharmacol (2013) 69:1275-1283 DOI 10.1007/s00228-012-1466-4

We would like to bring your attention to an error in the article "Warfarin dose prediction in children using pharmacometric bridging - comparison with published pharmacogenetic dosing algorithms" published in European Journal of Clinical Pharmacology volume 69 , year 2013, pages $1275-1283$. The error was purely a typo and has not influenced any of the results presented.

The typo is in Equation 1 (page 1276), which currently reads:

$\mathrm{CL}_{\mathrm{i}}=\mathrm{CL}_{\mathrm{s}} \cdot\left(\frac{\mathrm{BW}_{\mathrm{i}}}{\mathrm{BW}_{\mathrm{i}}}\right)^{0.75}$
After correction Equation 1 should read:

$\mathrm{CL}_{\mathrm{i}}=\mathrm{CL}_{\mathrm{s}} \cdot\left(\frac{\mathrm{BW}_{\mathrm{i}}}{\mathrm{BW}_{\mathrm{s}}}\right)^{0.75}$

where $\mathrm{CL}_{\mathrm{i}}$ represents the typical clearance in an individual with the bodyweight $\mathrm{BW}_{\mathrm{i}}$, and $\mathrm{CL}_{\mathrm{s}}$ represent the typical clearance in an individual with the bodyweight $\mathrm{BW}_{\mathrm{s}}$.

We sincerely apologies for any confusion this may have caused.

The online version of the original article can be found at doi:10.1007/ s00228-012-1466-4.

\footnotetext{
A.-K. Hamberg $(\varangle) \cdot$ M. Wadelius

Department of Medical Sciences, Clinical Pharmacology, Uppsala University, Entrance 61 3rd floor, SE-751 85 Uppsala, Sweden

e-mail: anna-karin.hamberg@medsci.uu.se

L. E. Friberg $\cdot$ E. N. Jonsson

Department of Pharmaceutical Biosciences, Uppsala University,

Uppsala, Sweden

K. Hanséus

Children's Heart Center, Skåne University Hospital, Lund, Sweden

B.-M. Ekman-Joelsson · J. Sunnegårdh

The Queen Silvia Children's Hospital, Sahlgrenska University

Hospital, Gothenburg, Sweden
A. Jonzon
Uppsala University Children's Hospital, Uppsala, Sweden
B. Lundell
Astrid Lindgren Children's Hospital, Stockholm, Sweden
E. N. Jonsson

Exprimo NV, Mechelen, Belgium
} 